\title{
Growing up: 10 years of publishing sustainability science research
}

\author{
Kazuhiko Takeuchi ${ }^{1,2,3} \cdot$ Saito Osamu ${ }^{2} \cdot$ Shruti Lahoti $^{2} \cdot$ Darek Gondor $^{2}$
}

Published online: 25 September 2017

(c) Springer Japan KK 2017

\section{Introduction}

Sustainability Science was launched in 2006 with an aim to build a new discipline, providing a platform for complex, interdisciplinary research. In the inaugural editorial message, Komiyama and Takeuchi (2006) defined sustainability science as a new emerging discipline which adopts "a comprehensive, holistic approach to identification of problems and perspectives involving the sustainability of these global, social, and human systems". They also emphasize "structuring knowledge for sustainability science" and a "transdisciplinary approach" as key drivers to promote this new discipline. The scientific community acted largely in unison as it became more and more disconnected from the societal and political forces shaping the sustainable development agenda (Kates et al. 2001). That article by Kates et al. in Science, and works such as Linking Social and Ecological Systems (Berkes and Folke 1998) before it, inspired several other academic platforms. The Proceedings of the National Academy of Sciences (PNAS) launched a section dedicated to sustainability science in 2006. Sustainability: science, policy and practice and other journals, academic networks, and more recently academic programs focusing on the discipline have taken root.

Saito Osamu

sust@unu.edu

$1 \quad$ Integrated Research System for Sustainability Science (IR3S), The University of Tokyo, Tokyo, Japan

2 United Nations University Institute for the Advanced Study of Sustainability (UNU-IAS), Tokyo, Japan

3 Institute for Global Environmental Strategies (IGES), Hayama, Japan
Ten years later, the field is no longer considered new. It is widely recognized and accepted as a bridge between various disciplines to address global challenges and more recently as a foundation of knowledge for achieving the sustainable development goals (SDGs). Over the last decade the discipline has emerged as a science for transition and innovation towards a sustainable society and is widely accepted not only by research communities from various disciplines but also stakeholders from business sectors. As per the findings of an Elsevier report on sustainability science in a global landscape, field research shows a tremendous growth rate of about $7.6 \%$ in all Scopus publications from 2009 to 2013, which is twice the average. Sustainability science research outputs attract $30 \%$ more citations than the average research paper (Elsevier and Sci Dev Net 2015).

The foundation for the sustainability science research community in Japan was set in 2005 when the Integrated Research System for Sustainability Science (IR3S: http:// en.ir3s.u-tokyo.ac.jp/) including its five partner universities was established at the University of Tokyo to promote integration and cooperation among diverse academic fields and across geographic and national borders with a particular focus on developing and enhancing top-flight academic programs in sustainability science. IR3S organized the first International Conference on Sustainability Science (ICSS) in Tokyo in 2009. That meeting strongly shaped the scope and content of the journal (Kauffman 2009). With the strong partnership between the University of Tokyo, Arizona State University, the Sapienza University of Rome, the United Nations University, and Stockholm University, ICSS has been organized seven times from 2009 to 2017: ICSS-2010 in Rome, Italy; ICSS-2012 in Arizona, USA; ICSS-2013 in Marseille, France; ICSS2015 in Tokyo, Japan; ICSS-2016 in Stellenbosch, South 
Table 1 Special feature topics of Sustainability Science

\begin{tabular}{lll}
\hline 2007 & Vol. 2 no. 2 & Policy sciences for sustainable development \\
2008 & Vol. 3 no. 1 & Sea-level rise \\
2009 & Vol. 4 no. 1 & Education for sustainable development \\
2010 & Vol. 5 no. 1 & Land use and ecosystems \\
& Vol. 5 no. 2 & Vulnerability, risk, and adaptation in a changing climate \\
2011 & Vol. 6 no. 1 & African regional perspectives \\
2012 & Vol. 7 sup. 1 & Sustainability science: bridging the gap between science and society \\
& Vol. 7 no. 2 & Socio-technological transitions towards sustainable energy and climate stabilization \\
2013 & Vol. 8 no. 3 & Understanding and managing global change in small islands \\
2014 & Vol. 9 no. 4 & New directions in sustainability science \\
2015 & Vol. 10 no. 2 & Pathways towards sustainable landscapes \\
& Vol. 10 no. 3 & Socially sustainable degrowth as a social-ecological transformation \\
& Vol. 10 no. 4 & The reality of transdisciplinary processes \\
2016 & Vol. 11 no. 1 & Weaving indigenous and sustainability sciences to diversify our methods (WIS2DOM) \\
& Vol. 11 no. 4 & Sustainable deltas: livelihoods, ecosystem services and policy implications \\
& Vol. 11 no. 5 & Traps! expanding thinking on persistent maladaptive states in pursuit of resilience \\
& Vol. 12 no. 1 & Sustainability and digitalization: a game changer? Possibilities, perils, pathways \\
& Vol. 12 no. 2 & Sustainability science for meeting Africa's challenges
\end{tabular}

Africa; and ICSS-2017 in Stockholm, Sweden. The outcomes of ICSS were published as the journal special features (SF) such as SF on "Sustainability science: bridging the gap between science and society" in 2012, and SF on "Sustainability science for meeting Africa's challenges" in 2017 (Table 1).

\section{Expansion}

The growth in sustainability science research reflects the critical importance of this evolving field, made possible through the efforts of a core group of sustainability scientists who use the journal to disseminate their work and volunteer their time as editors and reviewers. It is this core group of researchers and their partner institutions that have helped lift sustainability science, and Sustainability Science, to their current level of international recognition. Over the past decade the journal has published over 400 articles by authors from all corners of the globe, writing on variety of topics. The journal team is also growing in diversity of reach with expansion of our editorial board. We are privileged to work closely with our team of around 100 editors and advisors and around 2400 active reviewers.

\section{Impact and usage}

The reflection of this success can be seen in the rank of the journal among its peers, ranks of 55th in 229 Environmental Sciences journals and 13th in 31 Green and
Sustainable Science and Technology journals. The steady increase in Impact Factor is another indicator of journals progress as seen in Fig. 1, with a 2016 impact factor as 3.429 and 5-year impact factor 2016 as 4.321 . The increase in readership can be gauged by the increase in full text download of the journals apart from the institutional subscription and visit by geography as shown in Fig. 2. The journal is mainly popular in Europe and Asia Pacific region; however, in the past few years the readership is also increasing in Latin America and Africa. More than 1500 users regularly receive table of contents (ToC) alerts, a journal newsletter, or are connected on social media. Figure 3 reflects the speed, usage and overall impact of the journal.

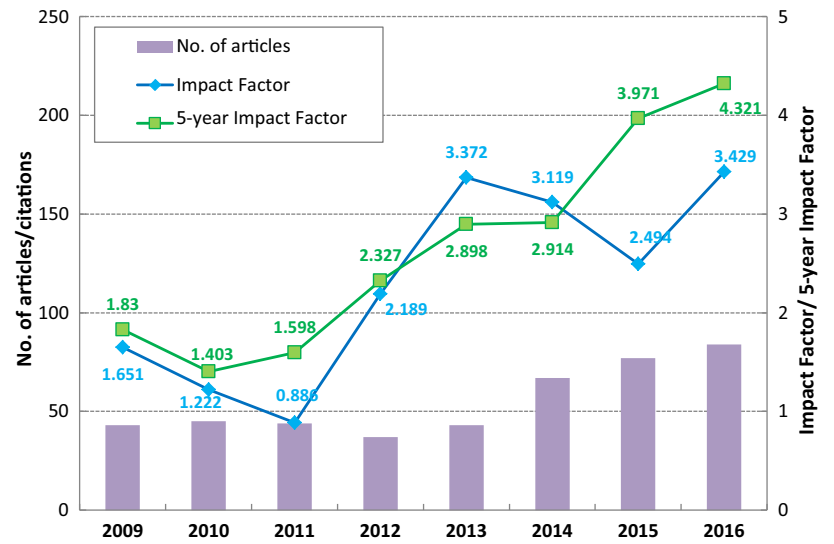

Fig. 1 Impact factor and 5-year impact factor of the journal from 2009 to 2016 

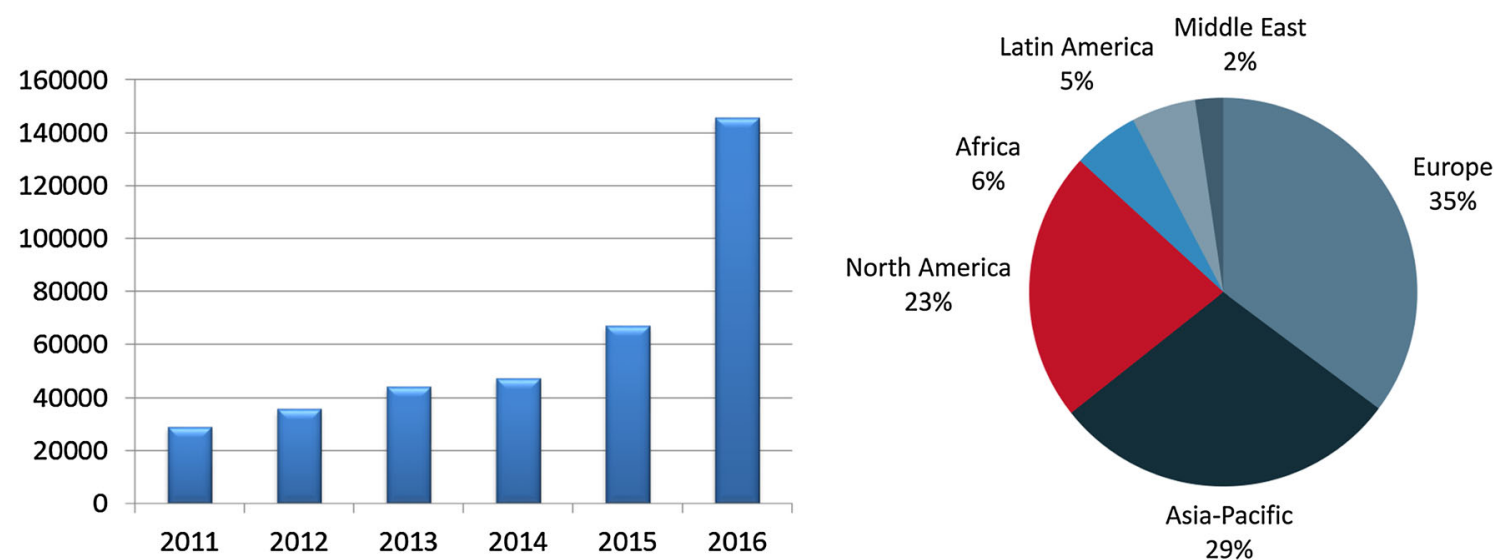

Fig. 2 Changes in full text downloads from 2011 to 2016 (left), and visits by geography in 2016 (right)

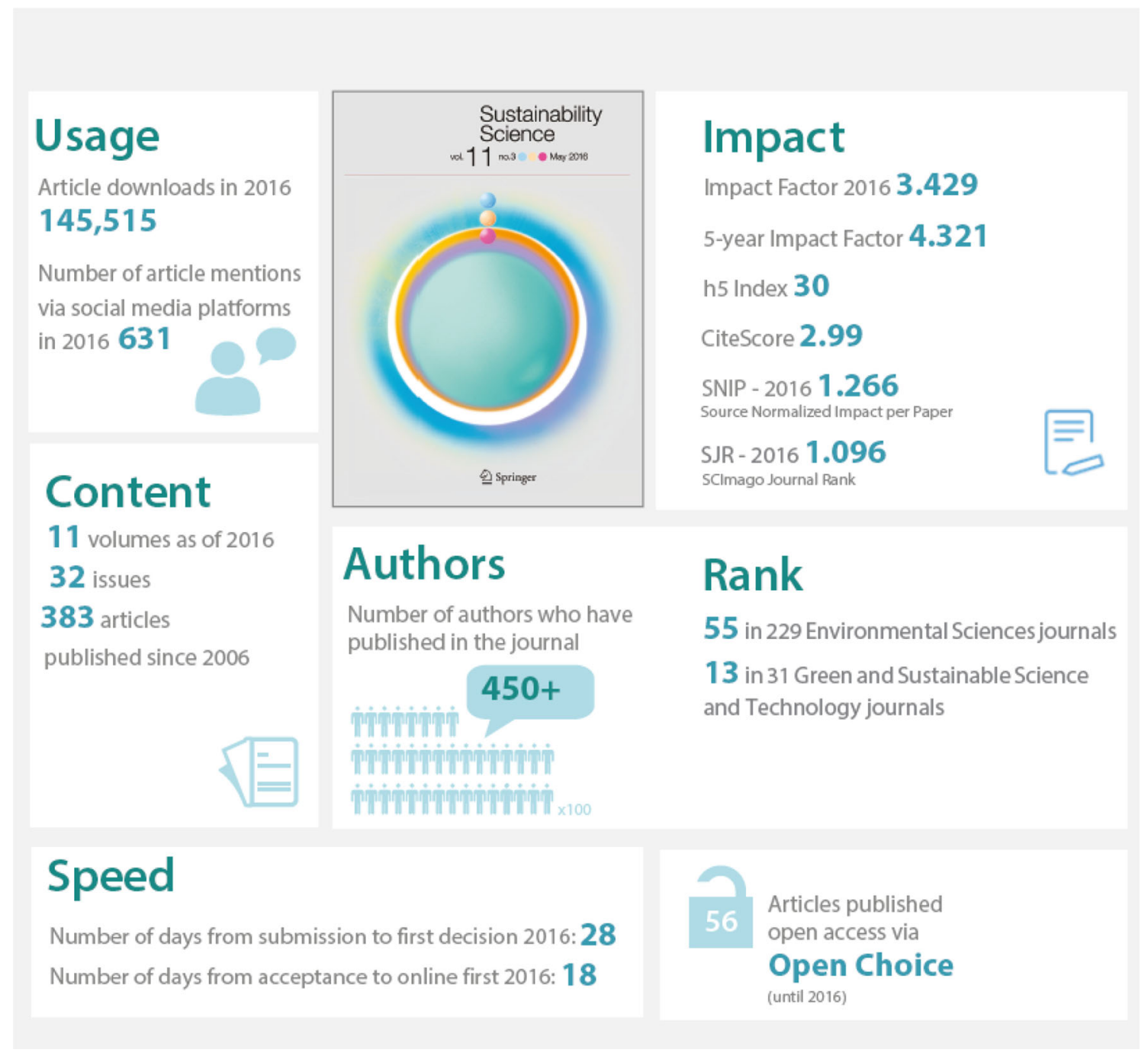

Fig. 3 Journals infographic (as of August 2017) 


\section{Networks and collaborations}

Collaborations among institutions and networks are emerging as strong conveners of researchers, bringing together scientist and technologist to addresses sustainability issues. The vision is to produce transdisciplinary outcomes and not just interdisciplinary efforts, aiming to break the barrier between academia, community and society (Kajikawa et al. 2007). We are supported by research networks such as the IR3S and the Sustainability Science Consortium (http://ssc-g.net/en/) in Japan, International Council for Science, Future Earth, Stockholm Resilience Center, Stockholm University, and others. Through these collaborations and association with partner universities such as Arizona State University, the journal benefits immensely from a diversity of geographies, cultures and ideas.

\section{Other initiatives}

We encourage publication on thematic topics by having special features (SF) that explore innovative ideas to tackle new global problems. Since 2007, the journal has published 19 special features (Table 1), and the editorial office constantly receives SF proposals. Venturing beyond the journals' research content, since 2012 we started to acknowledge our authors by initiating the "Sustainability Science Best Paper Awards" (Table 2). The aim is to recognize the contributions of researchers that further enhance the understanding of sustainability science and demonstrate high standards of scientific quality. The papers are selected by an editorial committee after the editorial office staff select finalists, based on performance criteria.

In this issue, we also present a new type of invited paper-a short commentary by selected authors who follow up on previously published research with new updates and emerging research priorities. Here are the seven chosen to appear in this feature.

Academic landscape of 10 years of Sustainability Science by Kajikawa et al. (2017) offers commentary on the character of the field's thematic clusters and research networks, and how they have shaped evolution of Sustainability Science journal. The authors find increasing integration of social systems into natural science and economic research.

Bridging divides in sustainability science by Lang et al. (2017) is a look at the future, especially the difficulties of working across disciplines, when transdisciplinarity is seen as a burden rather than adding value to projects. It takes a

Table 2 List of best papers awarded by Sustainability Science

2012

From complex systems analysis to transformational change: a comparative appraisal of sustainability science projects, Arnim Wiek et al.

Technological feasibility and costs of achieving a 50\% reduction of global GHG emissions by 2050: mid- and long-term perspectives,

Osamu Akashi and Tatsuya Hanaoka

Transdisciplinary research in sustainability science: practice, principles, and challenges, Daniel J. Lang et al.

2013

Understanding the impact of hydropower developments in the context of upstream-downstream relations in the Mekong river basin, Claudia Kuenzer et al.

Constructing sustainability science: emerging perspectives and research trajectories, Thaddeus R. Miller

Learning for change: an educational contribution to sustainability Science, Matthias Barth and Gerd Michelsen

2014

Assessing the sustainability of wheat-based cropping systems using simulation modeling: sustainability $=42$ ?, Carina Moeller et al.

Action, research and participation: roles of researchers in sustainability transitions, Julia M Wittmayer and Niko Schäpke

Biophysical suitability, economic pressure and land-cover change: a global probabilistic approach and in-sights for REDD, Bernardo BN Strassburg al.

2015

The real type and ideal type of transdisciplinary processes: part II-what constraints and obstacles do we meet in practice?, Roland W. Scholz and Gerald Steiner

Resilience thinking: a renewed system approach for sustainability science, Li Xu et al.

What lurks below the surface? Exploring the caveats of sea-level rise economic impact assessments, Scott Victor Valentine 2016

The role of learning in transdisciplinary research: moving from a normative concept to an analytical tool through a practice-based approach, Lotten Westberg and Merritt Polk

Human responses to social-ecological traps, Wiebren Johannes Boonstra et al.

Local ecological knowledge and incremental adaptation to changing flood patterns in the Amazon delta, Nathan Vogt et al. 
broad view towards doing better research in our field, making observations that reappear in the contributions that follow. Authors propose four "bridges" to overcome differences in disciplines, research theory and practice, range of stakeholders, and aligning research practice with sustainability values.

Facilitating data-intensive approaches to sustainability by Masaru Yarime (2017) is an example of bridging diverse stakeholders in smart city planning. Cities are centers of intense activity where assembling and integrating related data on material and energy use creates innovation. Yarime shows how universities can facilitate data sharing through research activities.

Sustainability trend in China and prospects of an assessment methodology by Keishiro Hara (2017) reviews sustainability indicators being used to show sustainability trends in China, and how they are being used as tools to propose and design solutions. Hara argues that the perspectives of future generations should be additionally taken into account in sustainability assessments.

A renewed focus on water security within the 2030 agenda for sustainable development by Zafar Adeel (2017) highlights the difficulty in achieving water related goals within the UN Sustainable Development Goals (SDG) agenda in socially and politically marginalized communities. He notes that "water insecure communities predominantly comprise populations in rural and per-urban areas and urban slums". Adeel sees creating an enabling environment through institutional learning, capacity development, and mobilization of financial resources as key elements of success.

Future science-policy agendas and partnerships for building a sustainable society in harmony with nature by Osamu Saito (2017) presents results of a survey to identify key science-policy agendas among stakeholders for governance of socio-ecological systems in the Asia Pacific region. This data collection is part of a project to create scenarios of plausible pathways we envision society taking, and assessing the consequences on ecosystems. It turns out that policy maker-researcher partnerships and the ecosystem management agenda were prioritized by respondents.

Sustainability science and the epistemic challenge by Bawden and Allenby (2017) close out the short commentary series with an exploration of the philosophical dimensions of sustainability science. They argue that due to the normative nature of sustainability, "its pursuit raises questions that are of an inherently philosophical nature", and that our worldviews affect how we interpret knowledge, nature and our presence within it, emphasizing the importance of values within a field experiencing accelerating rates of change within the systems it encompasses.

We invite readers to explore, and enjoy, this special feature on implementing the SDGs.

\section{The way forward}

If anything, the focus on complex global problems uncovers further subtleties about the interactions between the Earth, and us, its stewards. Interactions between distant places are increasingly widespread and influential, often leading to unexpected outcomes for sustainability (Liu et al. 2013). Telecouplings, as they are known, refer to various distant interactions which are increasingly important to understand present social-ecological systems. Including telecouplings, the interactions between nature and human have become and will be more complex and uncertain. At the same time, there are new opportunities enabled by new technologies such as self-driving transportation systems, sharing economy, artificial intelligence, digitization, smart buildings and cities, and big data accumulated by information and communication technology (ICT).

In 2016, the editorial office of Sustainability Science nominated Asara et al. (2015) entitled "Socially sustainable degrowth as a social-ecological transformation: repoliticizing sustainability" to Springer Nature's Change the World campaign which promotes sharing groundbreaking scientific findings that could help humanity and protect our planet (http://www.springernature.com/gp/ researchers/campaigns/change-the-world). The paper was the most clicked among 120 papers nominated by Springer Nature across journals in all disciplines. This suggests that it is critically important to understand the social and ecological limits to growth and the social-ecological transformation envisioned by the degrowth paradigm (Asara et al. 2015).

In addition, integration of different knowledge systems including indigenous and local (traditional) knowledge will be one of the new opportunities to be explored by sustainability science research. Johnson et al. (2016) stressed that "productive and reciprocal collaboration between Indigenous and sustainability sciences could create a new vision for sustaining resilient landscapes". Through strengthening the science-policy-society interface, and coproduction of knowledge as well as future scenarios with innovative policy options, new relationship between the sciences and society should be explored to lead effective actions for operationalizing and implementing SDGs from local, national, regional to global scales.

\section{References}

Adeel Z (2017) A Renewed focus on water security within the 2030 agenda for sustainable development. Sustain Sci 12(6) 
Asara V, Otero I, Demaria F, Corbera E (2015) Socially sustainable degrowth as a social-ecological transformation: repoliticizing sustainability. Sustain Sci 10:375-384

Bawden R, Allenby B (2017) Sustainability science and the epistemic challenge: some matters philosophical and why we ought to come to know them better. Sustain Sci 12(6)

Berkes F, Folke C (1998) Linking social and ecological systems for resilience and sustainability. In: Berkes F, Folke C, Colding J (eds) Linking social and ecological systems: management practices and social mechanisms for building resilience. Cambridge University Press, Cambridge, pp 1-25

Elsevier and Sci Dev Net (2015) Sustainability science in a global landscape. https://www.elsevier.com/research-intelligence/ research-initiatives/sustainability-2015. Accessed 15 Aug 2017

Hara K (2017) Sustainability trend in China and prospects of assessment methodology. Sustain Sci 12(6)

Johnson JT, Howitt R, Cajete G, Berkes F, Louis RP, Kliskey A (2016) Weaving Indigenous and sustainability sciences to diversify our methods. Sustain Sci 11:1-11

Kauffman J (2009) Advancing sustainability science: report on the International Conference on Sustainability Science (ICSS) 2009. Sustain Sci 4:233. doi:10.1007/s11625-009-0088-y
Kajikawa Y, Ohno J, Takeda Y et al (2007) Creating an academic landscape of sustainability science: an analysis of the citation network. Sustain Sci 2:221. doi:10.1007/s11625-007-0027-8

Kajikawa Y, Saito O, Takeuchi K (2017) Academic landscape of 10 years of sustainability science. Sustain Sci 12(6)

Kates RW, Clark WC, Corell R et al (2001) Sustainability science. Sci 292(5517):641-642

Komiyama H, Takeuchi K (2006) Sustainability science: building a new discipline. Sustain Sci 1:1-6

Lang DJ, Wiek A, von Wehrden H (2017) Bridging divides in sustainability science. Sustain Sci 12(6)

Liu J, Hull V, Batistella M, DeFries R et al (2013) Framing sustainability in a telecoupled world. Ecol Soc 18(2):26

Saito O (2017) Future science-policy agendas and partnerships for building a sustainable society in harmony with nature. Sustain Sci 12(6)

Yarime M (2017) Facilitating data-intensive approaches to innovation for sustainability: opportunities and challenges in creating smart cities. Sustain Sci 12(6) 